\title{
Mixing Apples and Oranges in Assessing Outcomes of Repetitive Transcranial Stimulation Meta-Analyses
}

Citation for published version (APA):

Brunoni, A. R., Arns, M., Baeken, C., Blumberger, D., Brunelin, J., Carpenter, L. L., Downar, J., Keeser, D., Langguth, B., Rachid, F., Sack, A. T., Vila-Rodriguez, F., \& Padberg, F. (2020). Mixing Apples and Oranges in Assessing Outcomes of Repetitive Transcranial Stimulation Meta-Analyses. Psychotherapy and Psychosomatics, 89(2), 106-107. https://doi.org/10.1159/000504653

Document status and date:

Published: 01/03/2020

DOI:

10.1159/000504653

Document Version:

Publisher's PDF, also known as Version of record

Document license:

Taverne

Please check the document version of this publication:

- A submitted manuscript is the version of the article upon submission and before peer-review. There can be important differences between the submitted version and the official published version of record.

People interested in the research are advised to contact the author for the final version of the publication, or visit the DOI to the publisher's website.

- The final author version and the galley proof are versions of the publication after peer review.

- The final published version features the final layout of the paper including the volume, issue and page numbers.

Link to publication

\footnotetext{
General rights rights.

- You may freely distribute the URL identifying the publication in the public portal. please follow below link for the End User Agreement:

www.umlib.nl/taverne-license

Take down policy

If you believe that this document breaches copyright please contact us at:

repository@maastrichtuniversity.nl

providing details and we will investigate your claim.
}

Copyright and moral rights for the publications made accessible in the public portal are retained by the authors and/or other copyright owners and it is a condition of accessing publications that users recognise and abide by the legal requirements associated with these

- Users may download and print one copy of any publication from the public portal for the purpose of private study or research.

- You may not further distribute the material or use it for any profit-making activity or commercial gain

If the publication is distributed under the terms of Article $25 \mathrm{fa}$ of the Dutch Copyright Act, indicated by the "Taverne" license above, 
Psychother Psychosom 2020;89:106-107

DOI: 10.1159/000504653

\section{Mixing Apples and Oranges in Assessing Outcomes of Repetitive Transcranial Stimulation Meta-Analyses}

\author{
Andre R.Brunoni ${ }^{\mathrm{a}}$ Martijn Arns ${ }^{\mathrm{b}}$ Chris Baeken ${ }^{\mathrm{c}-\mathrm{f}}$ \\ Daniel Blumberger $^{\mathrm{g}}$ Jerome Brunelin ${ }^{\mathrm{h}}$ Linda L.Carpenter ${ }^{\mathrm{i}}$ \\ Jonathan Downar ${ }^{\mathrm{j}}$ Daniel Keeser ${ }^{\mathrm{k}}$ Berthold Langguth ${ }^{\mathrm{I}}$ \\ Fady Rachid $^{\mathrm{m}}$ Alexander T. Sack ${ }^{\mathrm{n}}$ Fidel Vila-Rodriguez ${ }^{\circ}$ \\ Frank Padbergk
}

${ }^{a}$ Department of Psychiatry and Internal Medicine, Faculdade de Medicina da Universidade de São Paulo, São Paulo, Brazil; ${ }^{\mathrm{b}}$ Research Institute, Brainclinics Foundation, Nijmegen, The Netherlands; ${ }^{\circ}$ Ghent Experimental Psychiatry (GHEP) Lab, Ghent University, Ghent, Belgium; ' Department of Psychiatry and Medical Psychology, Ghent University, Ghent, Belgium; eDepartment of Psychiatry, Vrije Universiteit Brussel (VUB), Universitair Ziekenhuis Brussel (UZ Brussel), Brussels, Belgium; ${ }^{f}$ Department of Electrical Engineering, Eindhoven University of Technology, Eindhoven, The Netherlands; ${ }^{9}$ Center for Addiction and Mental Health and University of Toronto, Toronto, ON,

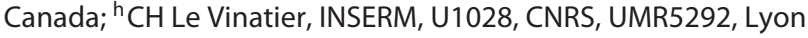
Neuroscience Research Center, PSYR2 Team, Université de Lyon, Lyon, France; 'Brown University Department of Psychiatry/ Butler Hospial, Providence, RI, USA; 'Department of Psychiatry and Institute of Medical Science, Faculty of Medicine, University of Toronto, Toronto, ON, Canada; ${ }^{2}$ Department of Psychiatry and Psychotherapy, University Hospital LMU Munich, Munich, Germany; 'Department of Psychiatry and Psychotherapy, University of Regensburg, Regensburg, Germany; m Private Practice, Geneva, Switzerland; ' Section Brain Stimulation and Cognition, Department of Cognitive Neuroscience, Faculty of Psychology and Neuroscience, Maastricht University and Department of Psychiatry and Neuropsychology, School for Mental Health and Neuroscience (MHeNs), Brain and Nerve Centre, Maastricht University Medical Centre+ (MUMC+), Masstricht, The Netherlands; ${ }^{\circ}$ Non-Invasive Neurostimulation Therapies Laboratory, Department of Psychiatry, Faculty of Medicine, The University of British Columbia,

Vancouver, BC, Canada

\section{Dear Editor,}

Amad et al. [1] have critically assessed the evidence base for therapeutic application of repetitive transcranial magnetic stimulation (rTMS) in neurological and psychiatric disorders based on the test of excess significance, which statistically compares the expected versus observed number of "positive" datasets. For estimating the effect size of rTMS, the authors selected two large random- ized clinical trials (RCTs) that were evaluated as "representative of the field" and "presenting low risk of bias." Afterwards, they compared the combined effect size of these trials with the combined effect size of all datasets for a given disorder. As more "positive" datasets were observed than expected, the authors concluded that "caution is warranted in accepting rTMS as an established treatment for neuropsychiatric disorders."

The whole field of brain stimulation, and rTMS in particular, is experiencing an expansion of the investigation of its clinical applications in neuropsychiatric disorders. In this context, it is of utmost importance to systematically and rationally appraise the literature to better guide patients, clinicians, and policy makers in their decisions. Thus, we appreciate the effort of Amad et al. [1] and also share some of their critical views. However, we would like to discuss important methodological issues that limit the study's overall conclusion.

First, the authors selected two RCTs to represent all rTMS interventions. However, these trials employed particular variants of TMS. For instance, Levkovitz et al. [2] employed the H1-coil rTMS ("deepTMS"), which uses a non-focal, bilateral method of brain stimulation [2] and is considered a distinct rTMS modality; whereas the study of Leuchter et al. [3], despite clearly presenting biases (e.g., attrition rate of $40 \%$ ), used a low-field magnetic stimulation modality. Both rTMS modalities are not commonly used in clinical practice and are delivered by equipment designed specifically for depression. In fact, high-frequency rTMS, the most used modality for depression, has an effect size at least two times higher than estimated by Amad et al. [1] according to recent meta-analyses [4, 5]. As the authors stated that the true effect size of an intervention is "exploratory by nature," it is surprising that they evaluated only specific subvariants of rTMS and did not consider other or additional RCTs, or carefully designed meta-analyses in their estimations.

Second, the authors wrote that the evidence of rTMS "appears [to be] strongly favorable for almost every condition [evaluated]." This is not supported by their own data. For instance, no evidence for this claim was found for any of the psychiatric disorders investigated, except for depression (but see above). For neurologic disorders, the issues arose from two specific meta-analyses: chronic neuropathic pain (18/25 "positive" datasets) and post-stroke depression (22/24 "positive" datasets). However, these studies were methodologically problematic. For instance, the post-stroke depression meta-analysis [6] included several datasets that are not internationally accessible and had low quality, whereas the chronic neuropathic pain meta-analysis [7] included many single-session rTMS trials, which evaluated only short-term rTMS effects and were not necessarily designed to evaluate long-term efficacy.

Third, the authors failed to grasp the particularities involved in different rTMS modalities. Critically, rTMS effects vary according to the frequency, intensity (defined as the percentage applied according to the resting motor threshold), number of pulses, number

\section{KARGER}

(C) 2019 S. Karger AG, Basel

karger@karger.com

www.karger.com/pps
Andre R. Brunoni, MD, PhD, Service of Interdisciplinary Neuromodulation Rua Dr. Ovidio Pires de Campos 785, 2o andar Ala Sul Instituto de Psiquiatria

São Paulo, SP 05403-000 (Brazil)

E-Mail brunowsky@gmail.com 
of sessions, coil design, and coil positioning [8]. For instance, some rTMS protocols, such as high-frequency rTMS and intermittent theta-burst stimulation, promote long-term excitatory changes; whereas others such as low-frequency rTMS and continuous theta-burst stimulation can exert inhibitory effects. Therefore, it is methodologically flawed to estimate rTMS effects among several neuropsychiatric disorders without taking into account that different rTMS protocols are employed for these disorders.

In sum, the issue of reproducibility is clearly relevant in rTMS research as in other domains of clinical neuroscience. Correspondingly, key research questions of rTMS efficacy should be addressed with adequately powered and well-designed clinical trials for new indications. However, we do not share the rather generalized conclusions that compared largely varying applications, which are as different as apples and oranges.

\section{Disclosure Statement}

A.R.B. receives research support from Brazilian Council of Scientific and Technological Development (CNPq) and University of São Paulo Medical School. F.V.-R. receives research support from CIHR, Brain Canada, Michael Smith Foundation for Health Research, Vancouver Coastal Health Research Institute, and inkind equipment support for this investigator-initiated trial from MagVenture. He has received honoraria for participation in the advisory board for Janssen. M.A. is unpaid director and owner of Research Institute Brainclinics and a minority shareholder in neuroCare Group (Munich, Germany). Research Institute Brainclinics received research funding from Brain Resource (Sydney, Australia), Urgotech (France), and neuroCare Group (Munich, Germany), and equipment support from Deymed, neuroConn, Brainsway, and Magventure. L.L.C. has received grant support for clinical research studies from Industry (Neosync, Neuronetics, Nexstim, AffectNeuro, and Janssen) and US government (National Institutes of Health). She has received consulting income from Janssen. J.D. has received grant support from the Arrell Family Foundation, the Buchan Family Foundation, Brain Canada, the Canadian Biomarker Integration Network in Depression, the Canadian Institutes of Health Research (CIHR), the Klarman Family Foundation, NIH, the Ontario Brain Institute, the Toronto General and Western Hospital Foundation, and the Weston Family Foundation; he has served as an advisor for BrainCheck, Restor- ative Brain Clinics, Neurostim TMS Centers, and TMS Neuro Solutions. F.P. is a member of the European Scientific Advisory Board of Brainsway Inc., Jerusalem, Israel, and has received speaker's honoraria from Mag\&More $\mathrm{GmbH}$ and the neuroCare Group. His lab has received support with equipment from neuroConn $\mathrm{GmbH}$, Ilmenau, Germany, and Mag\&More GmbH and Brainsway Inc., Jerusalem, Israel. J.B. was a member of the European Scientific Advisory Board of Brainsway Inc., Jerusalem, Israel.

\section{Funding Sources}

The authors did not receive any funding.

\section{References}

1 Amad A, Jardri R, Rousseau C, Larochelle Y, Ioannidis JPA, Naudet F. Excess significance bias in repetitive transcranial magnetic stimulation literature for neuropsychiatric disorders. Psychother Psychosom. DOI: $10.1159 / 000502805$.

2 Shen X, Liu M, Cheng Y, Jia C, Pan X, Gou Q, et al. Repetitive transcranial magnetic stimulation for the treatment of post-stroke depression: A systematic review and meta-analysis of randomized controlled clinical trials. J Affect Disord. 2017 Mar;211:65-74.

3 Jin Y, Xing G, Li G, Wang A, Feng S, Tang Q, et al. High Frequency Repetitive Transcranial Magnetic Stimulation Therapy For Chronic Neuropathic Pain: A Meta-analysis. Pain Physician. 2015 Nov;18(6):E102946.

4 Levkovitz Y, Isserles M, Padberg F, Lisanby SH, Bystritsky A, Xia G, et al. Efficacy and safety of deep transcranial magnetic stimulation for major depression: a prospective multicenter randomized controlled trial. World Psychiatry. 2015 Feb;14(1):64-73.

5 Leuchter AF, Cook IA, Feifel D, Goethe JW, Husain M, Carpenter LL, et al. Efficacy and safety of low-field synchronized transcranial magnetic stimulation (sTMS) for treatment of major depression. Brain Stimul. 2015 Jul-Aug;8(4):787-94.

6 Mutz J, Vipulananthan V, Carter B, Hurlemann R, Fu CH, Young AH Comparative efficacy and acceptability of non-surgical brain stimulation for the acute treatment of major depressive episodes in adults: systematic review and network meta-analysis. BMJ. 2019 Mar;364:11079.

7 Brunoni AR, Chaimani A, Moffa AH, Razza LB, Gattaz WF, Daskalakis ZJ, et al. Repetitive Transcranial Magnetic Stimulation for the Acute Treatment of Major Depressive Episodes: A Systematic Review With Network Meta-analysis. JAMA Psychiatry. 2017 Feb;74(2):143-52.

8 Brunoni AR, Sampaio-Junior B, Moffa AH, Aparício LV, Gordon P, Klein I, et al. Noninvasive brain stimulation in psychiatric disorders: a primer. Braz J Psychiatr. 2019 Jan-Feb;41(1):70-80. 